\title{
Effect of Ganoderma lucidum on memory and learning in mice
}

Najeeb Khatian ${ }^{1}$ and Muhammad Aslam $^{2^{*}}$ (D)

\begin{abstract}
Background: In traditional Chinese medicine Ganoderma lucidum is famous for its beneficial effect on nervous system. It was traditionally used to manage different neurological disorders. This study was designed to investigate the nootropic potential of the mushroom.

Methods: Nootropic activity was evaluated following the oral administration of two different doses (150 and 300 $\mathrm{mg} / \mathrm{kg})$ of ethanol extract of Ganoderma lucidum. Physostigmine $(0.1 \mathrm{mg} / \mathrm{kg})$ and Scopolamine $(0.4 \mathrm{mg} / \mathrm{kg})$ were used as positive and negative controls respectively. Distilled water was used as a control. Elevated plus maze and Morris water maze were used for the assessment of learning process. In elevated plus maze, initial transfer latency and retention transfer latency were assessed. In Morris water maze, TSTQ (time spent in target quadrant) and transfer latency were evaluated. For the assessment of locomotor activity, open field test was utilized. Furthermore, biochemical estimation of acetylcholinestrases (AchE) was performed by using Ellman's method.

Results: The results of the study show that the Ganoderma lucidum extract has significantly increased the time spent in target quadrant (TSTQ) and decreased the escape latency (EL) in Morris water maze model. Whereas, a decrease in the Initial Transfer Latency (ITL) and Retention Transfer Latency (RTL) was observed in elevated plus maze model. Conclusion: The present study showed that Ganoderma lucidum has physostigmine like effect on brain acetylcholinesterase (AchE) activity.
\end{abstract}

Keywords: Ganoderma lucidum, Nootropic activity, Memory, Physostigmine

\section{Background}

Memory is one of the most critical functions of the brain and a major process by which the things we experience and observe are recorded and utilized to react to the surroundings. It is considered as a fundamental unit for the survival of human beings [1]. The centrally acting cholinergic neuronal system is considered as the most essential system in the regulation of several important functions of the brain including memory and learning [2].

In the previous decades, Alzheimer's disease has got extreme consideration [3, 4]. Alzheimer's disease has been the sixth leading cause of the death in U.S [5]. Loss of cholinergic neurons in the nucleus basalis magnocellular of cortex is considered as hallmark of Alzheimer's disease [6]. Oxidative stress, neuroinflammation, and

\footnotetext{
* Correspondence: Pharmacologist1@yahoo.com

${ }^{2}$ Department of Pharmacology, Faculty of Pharmacy, University of Sindh, Jamshoro 76080, Pakistan

Full list of author information is available at the end of the article
}

disturbance in the lipid metabolism play vital role in the progression of Alzheimer's disease [7].

The impaired cognition in Alzheimer's disease is counteracted with the drugs which have tendency of improving the cholinergic neurotransmission [8,9]. Donepezil, rivastigmine, galantamine and memantine are most commonly used drugs to treat Alzheimer's disease [7].

Scopolamine is considered as main agent which causes memory impairment in animals by antagonizing the effect of acetylcholine at muscarinic receptors [10].

Medicinal mushrooms have got importance in treating various types of chronic and acute disorders, these mushrooms have wide acceptance in the treatment of infectious diseases for several decades $[1,11]$.

Ganoderma lucidum is a famous mushroom because of its therapeutic efficacy. It is the one out of all therapeutic mushrooms, which is examined by many researchers. Ganoderma lucidum has been used as a remedy for many diseases and disorders for 5000 years. The mushroom is considered as a major part of 
Traditional Chinese Medicine (TCM). It is called as Lingzhi and is thought to be "The Mushroom of Immortality" in Korea and China [3].

Ganoderma lucidum, is considered as "The king of herbs". It is a fungus which grows on different defunct and dead trees, especially willow, oak, sweet gum, maple and elm. Ganoderma lucidum has a long history of use for propelling life span and for a healthier life style in China, Japan, and other Asian countries. Ganoderma lucidum is generally known as Reishi [12].

Ganoderma lucidum possesses different pharmacological effects, including, calming, antiatherosclerotic, anti-inflammatory, analgesic, chemopreventive and anti-aging effect $[13,14]$. Radioprotective, cytotoxic, antitumor, antibacterial, sedative, hypolipidemic, antiviral (for HIV), antifibrotic, hepatoprotective and antioxidant activities have also been seen in the mushroom $[15,16]$. In the latest studies, Reishi has shown its effectiveness in the treatment of carcinoma, leukemia, diabetes and hepatitis [17].

This study was designed to evaluate the nootropic activity of ethanol extract of Ganoderma lucidum on normal and memory deficit mice.

\section{Materials and methods}

\section{Drugs and chemicals}

Ethanol extract of fruiting bodies and cracked spores Ganoderma lucidum in capsule form branded as ReishiMaxGLPTM, was purchased from Pharmanex Inc. (United States of America).

\section{Animals}

Male Swiss albino mice (Mus musculus) weighing about $22-25 \mathrm{~g}$ were utilized in this study. Thirty mice divided in five groups $(n=6)$ were used in this study. The animals were procured from Liaquat National Medical College, Karachi. The temperature of the area was kept 23 $\pm 0.5^{\circ} \mathrm{C}$. Water ad libitum was provided to the mice. Mice were acclimatized in laboratory environment before the start of the study.

\section{Animal handling}

The guidelines of National Institute of Health $(\mathrm{NIH}$, 8th edition) were followed throughout the performance of research experiments. Handling of the animals was done according to the requirements mentioned in "Guidelines for the care and use of laboratory animals $8^{\text {th }}$ edition" [18].

\section{Dose selection}

The selection of doses was made as per research literature, that is, $0.4 \mathrm{mg} / \mathrm{kg}$ for scopolamine, $0.1 \mathrm{mg} / \mathrm{kg}$ for physostigmine were used [19]. Ganoderma lucidum extract was given in two doses that is, $150 \mathrm{mg} / \mathrm{kg}$ and $300 \mathrm{mg} / \mathrm{kg}$ [20].

\section{Animal groups and drug administration}

The animals were divided in the following five groups:

Group I: Vehicle control group (administered distilled water $10 \mathrm{ml} / \mathrm{kg}$, p.o.)

Group II: Negative control group (administered scopolamine $0.4 \mathrm{mg} / \mathrm{kg}$, i.p.)

Group III: Treatment group (administered physostigmine $0.1 \mathrm{mg} / \mathrm{kg}$ i.p. + scopolamine $0.4 \mathrm{mg} / \mathrm{kg}$ i.p.)

Group IV: Treatment group (administered extract 150 $\mathrm{mg} / \mathrm{kg}$, p.o. + scopolamine $0.4 \mathrm{mg} / \mathrm{kg}$, i.p.)

Group V: Treatment group (administered extract 300 $\mathrm{mg} / \mathrm{kg}$, p.o. + scopolamine $0.4 \mathrm{mg} / \mathrm{kg}$, i.p.)

\section{Elevated plus maze}

Elevated plus maze (EPM) is considered as main model to evaluate learning and cognition in rodents. It is comprised of two open arms $(16 \times 5 \mathrm{~cm})$ and two enclosed arms of same size as of open arms, having walls of about $5 \mathrm{~cm}$. This instrument is protracted from a center $(5 \times 5$ $\mathrm{cm})$ and the instrument is elevated to the height of 25 $\mathrm{cm}$. On the initial day of the experiment, (10th day of dosing), every animal was settled at the edge of any of the open arms. Initial Transfer Latency (ITL) was noted down on the initial trials for each animal. Initial transfer latency is defined as the time in which the animal moves from one of the open arms into any of the two closed arms with its all limbs. When the animal did not enter any closed arms within $90 \mathrm{~s}$, the mouse was smoothly directed into one of the two closed arms and the ITL was assigned $90 \mathrm{~s}$. The animal was then allowed to explore the maze for $120 \mathrm{~s}$ and then placed back into its home cages [21]. The remembrance of this memory was then evaluated later twenty-four (24) hours after first training; this is termed as Retention Transfer Latency or RTL [22, 23].

\section{Morris water maze}

Morris water maze (MWM) is considered as accurate model for evaluating learning of task and evaluating ongoing memory in rodents. Here MWM was utilized which was consisted of round tank $60 \mathrm{~cm}$ wide and 25 $\mathrm{cm}$ tall. This round tank was filled with water and temperature of water was kept $25{ }^{\circ} \mathrm{C}$. The water was turned cloudy with nontoxic white colored dye. Tank was divided into four equal quadrants i.e. North, South, East and West, which were made on the tank by using two threads which were crossed in the middle perpendicularly to each other and were firmly attached on the top of the tank. In target quadrant of tank (Q4), a platform $(6 \times 6 \mathrm{~cm})$ was placed. The water level was $1 \mathrm{~cm}$ above the platform which made it opaque. Every mouse was subjected to search the submersed platform and to stay on platform for $20 \mathrm{~s}$. Every mouse was smoothly put in any quadrant (except Q4) during the trial session. The mouse was placed in such a way that it faced the 
wall of tank. After every trial the location of mouse was changed, and $120 \mathrm{~s}$ were assigned to every mouse to search submersed platform. The platform was kept untouched and the position was remained unaltered during the training session [24].

When the mouse was unable to find the platform in the prescribed period i-e $120 \mathrm{~s}$, was smoothly guided towards the platform and allowed mouse to stay on platform for $20 \mathrm{~s}$ [25].

Escape latency (EL) recorded from 6th till 9th day of administration of drug for each animal. Trials for four consecutive days were done on every mouse. EL is defined as the period in which animal start moving from starting quadrant in search of hidden platform in the target quadrant. Training session for four consecutive trial days were done according to following pattern.

1st Day: Q1, Q2, Q3 and Q4.

2nd Day: Q2, Q3 Q4 and Q1.

3rd Day: Q3, Q4, Q1 and Q2.

4th Day: Q4, Q1, Q2 and Q3.

* "Q" is denoted for Quadrant.

After Escape latency session and testing, TSTQ (time spent in target quadrant) was noted. The platform was removed from the tank and each mouse could swim freely for $300 \mathrm{~s}$. The average time spent in each quadrant was noted. The average time in target quadrant (Q4) was also recorded in which the mouse could find the removed platform. This finding of platform is considered as a sign of memory retrieval. The observer stood in the same position throughout the training and test days $[24,25]$.

\section{Open field test}

To rule out the effect of the extract on motor activity, we examined ambulatory behavior of the animals in open field test. An open-field is a wooden box ( $45 \times$ $45 \times 40 \mathrm{~cm}$ ) with the floor partitioned into 16 squares. Every mouse was settled at the central square of the field and then ambulation (number of squares crossed) was noted for $10 \mathrm{~min}$. This ambulation will represent the locomotor activity of the mice $[26,27]$.

Biochemical estimations of cholinergic status in mouse brain At the end of the study, the mice were sacrificed. The whole brain was collected and subjected to homogenization in a glass homogenizer containing $10 \mathrm{ml}$ of $0.9 \%$ of $\mathrm{NaCl}$ solution and homogenized in an ice bath. The homogenate was then placed in the centrifugation machine set at 3000 $\mathrm{rpm}$ for $10 \mathrm{~min}$. The centrifugation caused the presence of cloudy supernatant liquid which was then used for detection of cholinesterase level in the brain [28].

To determine cholinesterase levels in brain of mouse the Ellman method was adopted. The method involves the acetylcholine iodide from and dithiobisnitrobenzoate. The reaction between dithiobisnitrobenzoate and acetylcholine iodide resulted in formation of thiocholine which formed yellow colour appearance and this yellow coloured precipitate formation in the reaction was considered as an end point of the method. The spectrophotometric analysis was done to determine rate of thiocholine formation from acetylcholine iodide in the presence of tissue cholinesterase and 5,5'-Dithiobis-(2-Nitrobenzoic Acid) (DTNB) was treated with the brain sample and the optical density (OD) of yellow colour compounds formed during the reaction was measured in spectrophotometer at the wavelength of $412 \mathrm{~nm}$ every minute [29].

\section{Statistical analysis}

The data were presented as mean \pm standard error of mean (SEM). The data were analyzed by one-way ANOVA followed by Tukey's post hoc test. A probability level of 0.05 or less was accepted as significant.

\section{Results \\ Effect of Ganoderma lucidum on initial transfer latency (ITL) in EPM}

Initial transfer latency of the scopolamine treated animals was increased significantly when compared with control group. Whereas, initial transfer latency of mice treated with physostigmine, Ganoderma lucidum extract $150 \mathrm{mg} /$ $\mathrm{kg}$ and $300 \mathrm{mg} / \mathrm{kg}$ decreased when compared with scopolamine group. It was further observed that Ganoderma lucidum showed more significant decrease at the dose of 300 $\mathrm{mg} / \mathrm{kg}$ when compared with $150 \mathrm{mg} / \mathrm{kg}$ group (Fig. 1a).

Furthermore, retention transfer latency was increased significantly when compared with control group. Co-administration of scopolamine with Ganoderma lucidum extracts at both doses, the retention transfer latency was decreased significantly when compared with the mice in which scopolamine alone was administered. Physostigmine co-administered with scopolamine treated group also shown decrease in retention transfer latency when compared with scopolamine alone treated animals (Fig. 1b).

\section{Effect of Ganoderma lucidum on TSTQ (time spent in target quadrant) in the Morris water maze}

The results show that the time spent in target quadrant of Morris water maze was significantly decreased in the mice treated with scopolamine when compared with control group. On other hand, the mice in which Ganoderma lucidum extract was co-administered with scopolamine showed significant increase in time spent in target quadrant when compared with scopolamine alone administered group. This has proved that Ganoderma lucidum extract has potential of increasing the retention time of ongoing learning memory (Fig. 2). 

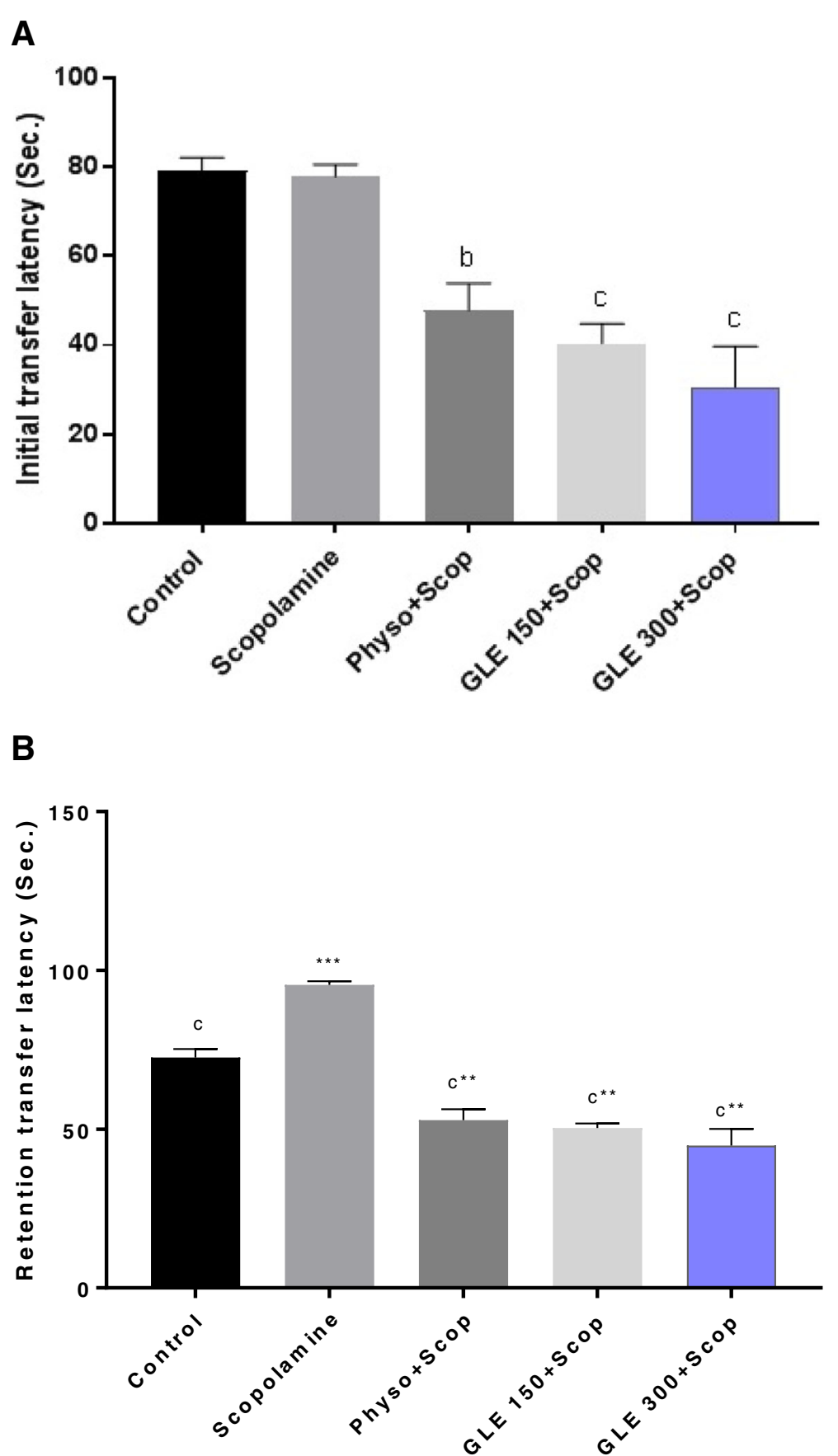

Fig. 1 a Effect of Ganoderma lucidum on Initial Transfer Latency (ITL) in EPM. Animals per group $(n)=6$; The values are mean \pm SEM (One-way ANOVA followed by Tukey's Post hoc test). ap $<0.05, \mathrm{~b} p<0.01, \mathrm{cp}<0.001$ when compared with scopolamine alone treated group. ${ }^{*} p<0.05,{ }^{* *} p<0.01$, *** $p<0.0001$ when compared with DW treated (control) group DW, distilled water; GLE 150, Ganoderma lucidum extract (150 mg/kg); GLE 300 , Ganoderma lucidum extract 300/kg; Scop, Scopolamine; Physo, Physostigmine. b Effect of Ganoderma lucidum on retention transfer latency (RTL) in EPM. Animals per group $(n)=6$; The values are mean \pm SEM (One-way ANOVA followed by Tukey's Post hoc test). ap $<0.05, b p<0.01, c p<0.001$ when compared with scopolamine alone treated group. ${ }^{*} p<0.05,{ }^{* *} p<0.01,{ }^{* * *} p<0.0001$ when compared with DW treated (control) group DW, distilled water; GLE 150, Ganoderma lucidum extract (150 mg/kg); GLE 300, Ganoderma lucidum extract 300/kg; Scop, Scopolamine; Physo, Physostigmine 


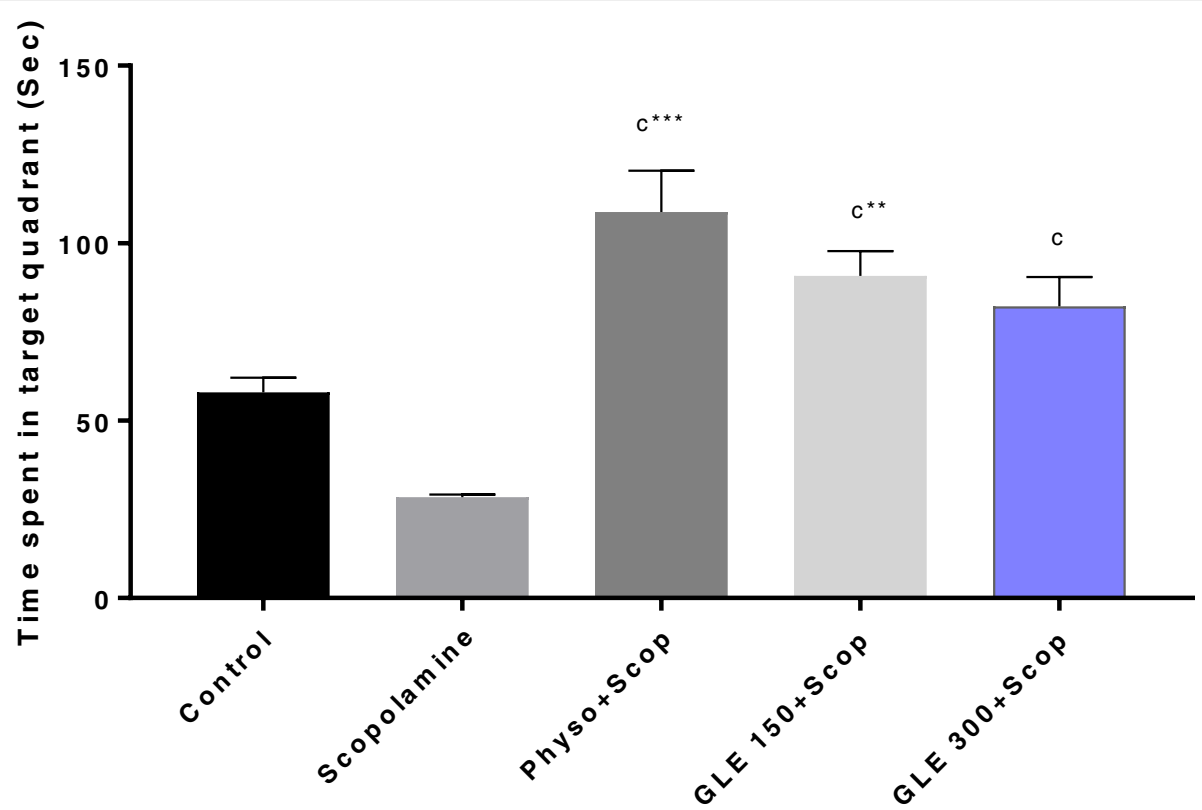

Fig. 2 Effect of Ganoderma lucidum on time spent in target quadrant (TSTQ) in MWM on 10th day of the study. Animals per group (n)=6; The values are mean \pm SEM (One-way ANOVA followed by Tukey's Post hoc test). ap $<0.05, b p<0.01, c p<0.001$ when compared with scopolamine alone treated group. ${ }^{*} p<0.05,{ }^{* *} p<0.01,{ }^{* * *} p<0.0001$ when compared with DW treated (control) group DW, distilled water; GLE 150, Ganoderma lucidum extract (150 mg/kg); GLE 300, Ganoderma lucidum extract 300/kg; Scop, Scopolamine; Physo, Physostigmine

The Escape Latency (EL) of different groups on 6th to 9th day of drug administration was also assessed. It was observed that on 6th day of the drug administration the escape latency of scopolamine alone treated animals was significantly increased when compared with control group. Co-administration of Ganoderma lucidum extract with scopolamine showed significant decrease in EL when compared with scopolamine alone treated mice on 6th and 9th day of the study (Table 1).

\section{Effect of Ganoderma lucidum on brain acetylcholinesterase (AchE) activity}

The results of the activity of AchE in mice brain suggested that scopolamine alone treated group has significantly increased brain AchE activity when compared with control group. Ganoderma lucidum extract, co-administered with scopolamine, and physostigmine co-administered with scopolamine, have significantly reduced the brain AChE activity in mice brain when compared with the scopolamine alone treated group (Fig. 3).

Effect of Ganoderma lucidum on locomotor activity in mice The results show that the locomotor activity of the different groups was similar when compared with control group and scopolamine induced memory deficit mice. This showed that Ganoderma lucidum extract has no effect on the motor activity of the mice (Fig. 4).

\section{Discussion}

Numerous scientific studies have been carried on Ganoderma lucidum for evaluating the pharmacological activities of the mushroom. This research was performed to evaluate the nootropic effect of the ethanol extract of Ganoderma lucidum in memory impaired swiss albino male mice. The memory was impaired by using scopolamine. Scopolamine is an alkaloidal drug which is extracted out from Datura stramonium. Scopolamine has tendency to impair memory in humans and animals, that is why it is used to cause long term or short-term memory impairment in rodents [30].

Learning process and memory in rodents is mainly evaluated by using elevated plus maze (EPM) model. It is considered as the validated model for the assessment of memory [29]. Transfer Latency (TL) of this model is found to be useful parameter for the assessment of cognition. TL is basically time taken by the rodent to shift itself into one of the closed arms from the open arms. In EPM, acquisition (learning) can be considered as transfer latency on first day trials and the retention/consolidation (memory) is assessed after $24 \mathrm{~h}$.

Ganoderma lucidum significantly reduced the Initial Transfer Latency (ITL) on 10th day of the treatment. Moreover, Ganoderma lucidum also significantly reduced the Retention Transfer Latency (RTL) on 11th day of the treatment after administration of scopolamine for the impairment of memory, indicating that 
Table 1 Effect of Ganoderma lucidum on Escape Latency (sec) in Morris Water Maze

\begin{tabular}{llllll}
\hline Treatment group & Dose & EL (Sec) Day 6 & EL (Sec) Day 7 & EL (Sec) Day 8 & EL (Sec) Day 9 \\
\hline Control & $10 \mathrm{ml} / \mathrm{Kg}$ & $28.4 \pm 2.4$ & $14.4 \pm 1.2$ & $13.2 \pm 1.1$ & $12.4 \pm 0.9$ \\
Scopolamine & $0.4 \mathrm{mg} / \mathrm{Kg}$ & $70.6 \pm 2.5^{* * *}$ & $71.6 \pm 3.4^{* * *}$ & $69.6 \pm 4.4^{* * *}$ & $67.6 \pm 4.8^{* * *}$ \\
Physo + Scop & $0.1 \mathrm{mg} / \mathrm{Kg}+0.4 \mathrm{mg} / \mathrm{Kg}$ & $27.4 \pm 1.9$ & $12.8 \pm 0.9$ & $11.8 \pm 0.9^{\mathrm{c}}$ & $11.0 \pm 0.8^{\mathrm{c}}$ \\
GLE $150 \mathrm{mg}+$ Scop & $150 \mathrm{mg} / \mathrm{Kg}+0.4 \mathrm{mg} / \mathrm{Kg}$ & $29.4 \pm 2.7$ & $26.4 \pm 1.8$ & $12.8 \pm 0.8$ & $13.6 \pm 0.8^{\mathrm{c}}$ \\
GLE $300 \mathrm{mg}+$ Scop & $300 \mathrm{mg} / \mathrm{Kg}+0.4 \mathrm{mg} / \mathrm{Kg}$ & $27 \pm 3.5$ & $23.2 \pm 2.0$ & $10.8 \pm 0.5^{\mathrm{c}^{* *}}$ & $10.0 \pm 0.3^{\mathrm{c}^{* *}}$ \\
\hline
\end{tabular}

Animals per group $(n)=6$; The values are mean \pm SEM (One-way ANOVA followed by Tukey's Post hoc test)

${ }^{\mathrm{a}} p<0.05,{ }^{\mathrm{b}} p<0.01,{ }^{\mathrm{c}} p<0.001$ when compared with scopolamine alone treated group

${ }^{*} p<0.05, * * p<0.01, * * * p<0.0001$ when compared with DW treated (control) group

DW distilled water, GLE 150 Ganoderma lucidum extract (150 mg/kg), GLE 300 Ganoderma lucidum extract 300/kg, Scop Scopolamine, Physo Physostigmine

Ganoderma lucidum improved the learning task and retained the information $[10,21,30]$.

In Morris water maze, a decrease in escape latency (EL) during training and an increase in time spent in the target quadrant during retrieval indicated improvement of learning and memory respectively; and vice versa. Ganoderma lucidum did not produce any significant alteration in locomotor functions of the animals when compared with distilled water treated control group, hence, the drug did not show any motor effects. Therefore, memory boosting activity of Ganoderma lucidum is specific and not false positive.

Scopolamine induced memory impairment causes increment in AchE action and oxidative stress in brain. Furthermore, it is believed that scopolamine has got tendency to hinder the neurogenesis process of the brain which causes impairment in cognition [21]. Many studies have shown that scopolamine alters the process of receiving, collecting and remembrance of information.
Drugs which have potential of increasing the cholinergic neuronal activity, are effective against memory impairment. Physostigmine is one of the drugs which increases cholinergic neuronal activity in brain and can combat the memory impairment [30].

Acetylcholinesterase activity was analyzed in the brain sample of mice. This marker enzyme is essential for detecting the cholinergic status in the brain [31]. The acetylcholinesterase determination has supported the results of elevated plus maze and Morris water maze test activity of mice in which the statistical reduction in the AChE activity caused the increment in the acetylcholine level in the brain of the mouse which resulted in increased function of memory. Therefore, the current study suggests that the ethanol extract of Ganoderma lucidum has dose dependent potential on cholinergic neuronal system and this resulted in elevating the brain acetylcholine level which resulted in improvement of memory function [30, 32].

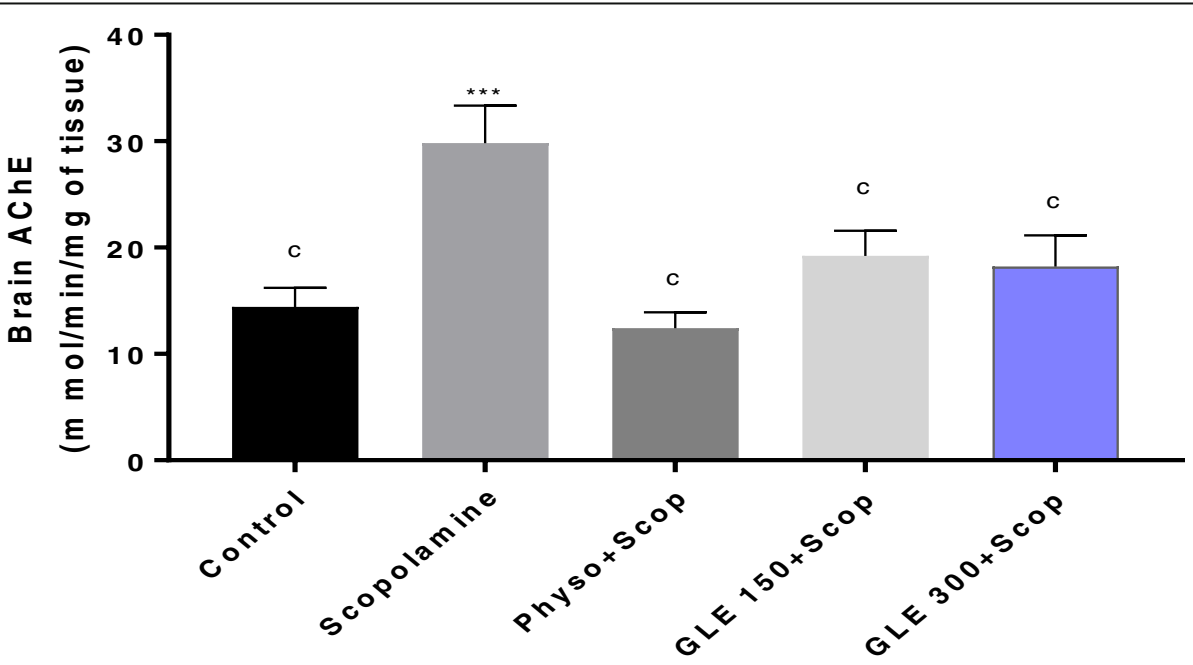

Fig. 3 Effect of Ganoderma lucidum on brain acetylcholinesterase in mice. Animals per group $(n)=6$; The values are mean \pm SEM (One-way ANOVA followed by Tukey's Post hoc test). ap $<0.05$, bp $<0.01, \mathrm{cp}<0.001$ when compared with scopolamine alone treated group. ${ }^{*} p<0.05,{ }^{*} p<0.01$, ${ }^{* * *} p<0.0001$ when compared with DW treated (control) group DW, distilled water; GLE 150, Ganoderma lucidum extract (150 mg/kg); GLE 300, Ganoderma lucidum extract 300/kg; Scop, Scopolamine; Physo, Physostigmine 


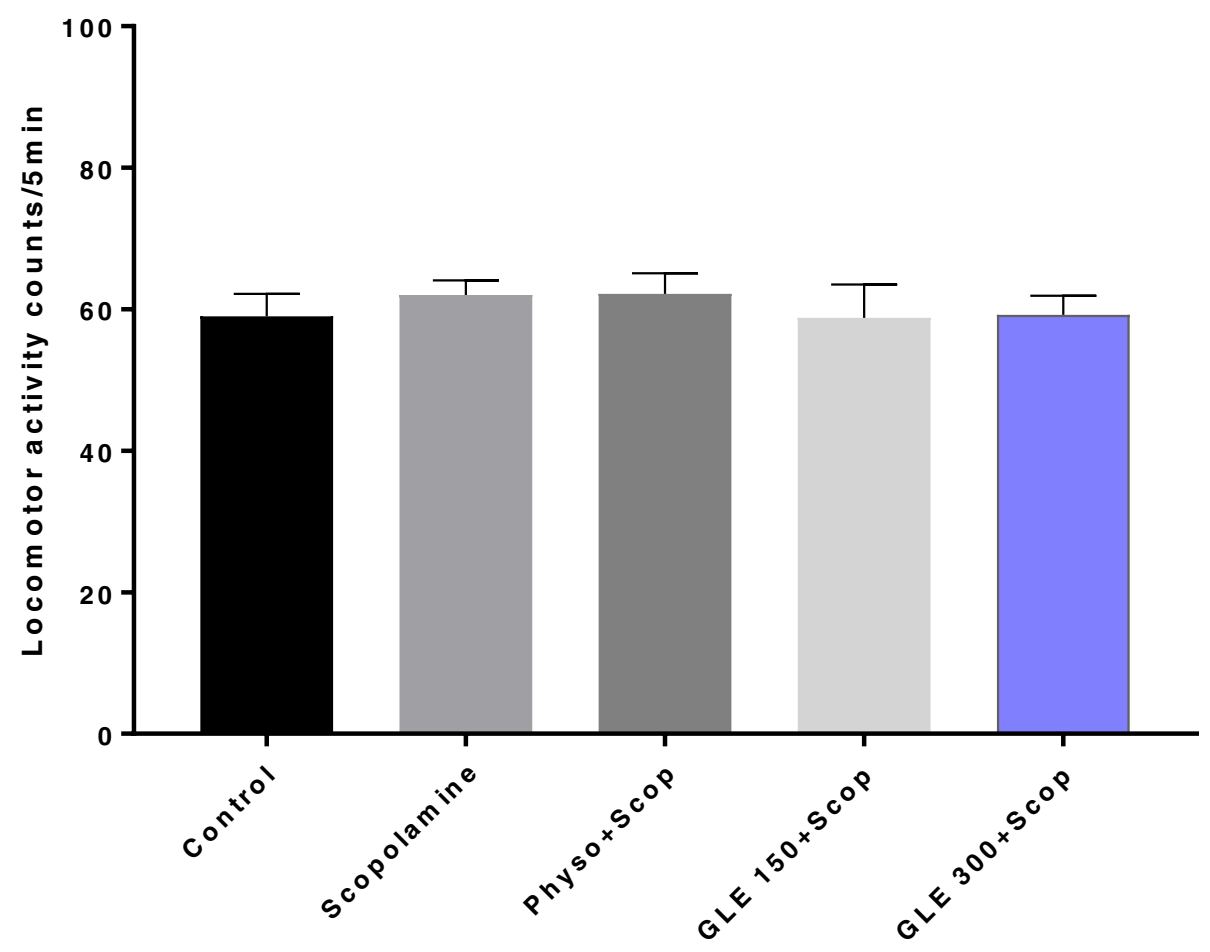

Fig. 4 Effect of Ganoderma lucidum on locomotor activity of mice. Animals per group $(n)=6$; The values are mean \pm SEM (One-way ANOVA followed by Tukey's Post hoc test). ap $<0.05$, bp $<0.01, \mathrm{cp}<0.001$ when compared with scopolamine alone treated group. ${ }^{*} p<0.05$, ${ }^{* *} p<0.01$, *** $p<0.0001$ when compared with DW treated (control) group DW, distilled water; GLE 150, Ganoderma lucidum extract (150 mg/kg); GLE 300, Ganoderma lucidum extract 300/kg; Scop, Scopolamine; Physo, Physostigmine

\section{Conclusion}

The study has revealed that ethanol extract of Ganoderma lucidum has nootropic potential and has capability of improving the memory of learning and ongoing tasks. Furthermore, the results of the study indicate that ethanol extract of Ganoderma lucidum exerts reversal action on scopolamine induced impaired memory and can be used as an agent for enhancing the cognition pattern.

\section{Abbreviations}

AchE: Acetylcholinestrases; ANOVA: Analysis of variance; CNS: Central nervous system; EL: Escape latency; EPM: Elevated plus maze; GLE: Ganoderma lucidum extract; Kg: Kilogram; Mg: Milligram; MWM: Morris water maze; Rpm: Rotations per minute; SEM: Standard error of mean; TL: Transfer latency; TSTQ: Time spent in target quadrant

\section{Acknowledgements}

Not applicable.

\section{Funding}

This research study was not granted any specific fund.

Availability of data and materials

Not applicable.

\section{Authors' contributions}

Study design and supervision, analysis of data, graphical representation, interpretation of results and drafting manuscript were done by MA. Sample collection and laboratory experiments were performed by NK. Both authors read and approved the final manuscript.
Ethics approval and consent to participate

Handling of the animals was done according to the requirements mentioned in "Guidelines for the care and use of laboratory animals 8th edition". Prior approval of the ethical review committee of Ziauddin University was taken before starting this research study.

\section{Consent for publication}

Not applicable.

\section{Competing interests}

The authors declare that they have no competing interests.

\section{Publisher's Note}

Springer Nature remains neutral with regard to jurisdictional claims in published maps and institutional affiliations.

\section{Author details}

${ }^{1}$ Department of Pharmacology, Faculty of Pharmacy, Ziauddin University, Karachi 75600, Pakistan. ${ }^{2}$ Department of Pharmacology, Faculty of Pharmacy, University of Sindh, Jamshoro 76080, Pakistan.

Received: 13 November 2018 Accepted: 3 January 2019 Published online: 11 February 2019

\section{References}

1. Kaur H, Singh D, Singh B, Goel RK. Anti-amnesic effect of Ficus religiosa in scopolamine-induced anterograde and retrograde amnesia. Pharm Biol. 2010:48(2):234-40.

2. Henneges C, Reed C, Chen YF, Dell'Agnello G, Lebrec J. Describing the sequence of cognitive decline in Alzheimer's disease patients: results from an observational study. J Alzheimers Dis. 2016;52(3):1065-80.

3. Iriti M, Vitalini S, Fico G, Faoro F. Neuroprotective herbs and foods from different traditional medicines and diets. Molecules. 2010;15(5):3517-55. 
4. Knopman DS. Alzheimer disease biomarkers and insights into mild cognitive impairment. Neurology. 2013;80(11):978-80.

5. Lambracht-Washington D, Rosenberg RN. Anti-amyloid-beta to tau-based immunization: developments in immunotherapy for Alzheimer's disease. Immunotargets Ther. 2013;2:105.

6. Sharma D, Puri M, Tiwary AK, Singh N, Jaggi AS. Antiamnesic effect of stevioside in scopolamine-treated rats. Indian J Pharmacol. 2010;42(3):164-7.

7. Chakravarthy M, Chen S, Dodd PR, Veedu RN. Nucleic acid-based theranostics for tackling Alzheimer's disease. Theranostics. 2017;7(16):3933-47.

8. Aslam M, Sultana N. Nootropic activity of Vitis vinifera juice in Normal and memory-impaired mice using spatial learning and recognition memory paradigms. Turk J Pharm Sci. 2015;12(3):327-36.

9. Kanwal A, Mehla J, Kuncha M, Naidu VG, Gupta YK, Sistla R. Anti-amnesic activity of Vitex negundo in scopolamine induced amnesia in rats. Pharmacology \& Pharmacy. 2010;1(01):1-8

10. Choi YJ, Yang HS, Jo JH, Lee SC, Park TY, Choi BS, Seo KS, Huh CK. Antiamnesic effect of fermented Ganoderma lucidum water extracts by lactic acid bacteria on scopolamine-induced memory impairment in rats. Prev Nutr Food Sci. 2015;20(2):126-32.

11. Aslam M, Najam R. A review of pharmacognostical, phytochemical and pharmacological properties of Lagenaria siceraria: a miracle herb. Int J Biomed Adv Res. 2013;4(5):266-74.

12. Wachtel-Galor S, Szeto YT, Tomlinson B, Benzie IF. Ganoderma lucidum ('Lingzhi'); acute and short-term biomarker response to supplementation. Int J Food Sci Nutr. 2004:55(1):75-83.

13. Wasser SP. Reishi or Ling Zhi (Ganoderma lucidum). In: Encyclopedia of dietary supplements, vol. 1; 2005. p. 603-22.

14. Wachtel-Galor S, Benzie IF. Herbal medicine: biomolecular and clinical aspects; 2011.

15. Batra P, Sharma AK, Khajuria R. Probing Lingzhi or Reishi medicinal mushroom Ganoderma lucidum (higher basidiomycetes): a bitter mushroom with amazing health benefits. Int J Med Mushrooms. 2013;15(2):127-43.

16. Zhu XL, Liu JH, Li WD, Lin ZB. Promotion of myelopoiesis in myelosuppressed mice by Ganoderma lucidum polysaccharides. Front Pharmacol. 2012;3(20):1-7.

17. Gill BS, Sharma P, Kumar R, Kumar S. Misconstrued versatility of Ganoderma lucidum: a key player in multi-targeted cellular signaling. Tumor Biol. 2016; 37(3):2789-804.

18. Garber J, Barbee W, Bielitzki J, Clayton L, Donovan J, Kohn D, Lipman N, Locke P, Melcher J, Quimby F, Turner P, Wood G, Würbel H. Guidelines for care and use of laboratory animals. 8th ed. Washington: The National Academies Press; 2011.

19. Bigoniya P, Singh S, Singh CS, Shukla A. Anti-anemic potential estimation on mice and characterization of flavonoids using high performance thin layer chromatography in Wrightia tinctoria bark fraction. Journal of Natural Pharmaceuticals. 2013;4(1):47.

20. Na K, Li K, Sang T, Wu K, Wang Y, Wang X. Anticarcinogenic effects of water extract of sporoderm-broken spores of Ganoderma lucidum on colorectal cancer in vitro and in vivo. Int J Oncol. 2017;50(5):1541-54.

21. Itoh J, Nabeshima T, Kameyama T. Utility of an elevated plus-maze for the evaluation of memory in mice: effects of nootropics, scopolamine and electroconvulsive shock. Psychopharmacology. 1990;101(1):27-33.

22. Kim KS, Zhao TT, Shin KS, Park HJ, Cho YJ, Lee KE, Kim SH, Lee MK. Gynostemma pentaphyllum ethanolic extract protects against memory deficits in an MPTP-lesioned mouse model of Parkinson's disease treated with L-DOPA. J Med Food. 2017;20(1):11-8.

23. Sodhi RK, Jaggi AS, Singh N. Animal models of dementia and cognitive dysfunction. Life Sci. 2014;109(2):73-86.

24. Komaki A, Karimi SA, Salehi I, Sarihi A, Shahidi S, Zarei M. The treatment combination of vitamins $E$ and $C$ and astaxanthin prevents high-fat diet induced memory deficits in rats. Pharmacol Biochem Behav. 2015;131:98-103.

25. Schimanski LA, Barnes CA. Insights into age-related cognitive decline: coupling neurophysiological and behavioral approaches. In: The Maze Book. New York: Humana Press; 2015. p. 121-42.

26. Liao JC, Tsai JC, Liu CY, Huang HC, Wu LY, Peng WH. Antidepressant-like activity of turmerone in behavioral despair tests in mice. BMC Complement Altern Med. 2013;13(1):299.

27. Lee MS, Kim YH, Park WS, Ahn WG, Park OK, Kwon SH, Morita K, Shim I, Her S. Novel antidepressant-like activity of propolis extract mediated by enhanced glucocorticoid receptor function in the hippocampus. Evid Based Complement Alternat Med. 2013;2013:217853.
28. Sujith K, Darwin CR, Suba V. Memory-enhancing activity of Anacyclus pyrethrum in albino Wistar rats. Asian Pac J Trop Dis. 2012;2(4):307-11.

29. Ellman GL, Courtney KD, Andres $V$ Jr, Featherstone RM. A new and rapid colorimetric determination of acetylcholinesterase activity. Biochem Pharmacol. 1961;7(2):88-95.

30. Kouémou NE, Taiwe GS, Moto FC, Pale S, Ngoupaye GT, Njapdounke JS, Nkantchoua GC, Pahaye DB, Bum EN. Nootropic and neuroprotective effects of dichrocephala integrifolia on scopolamine mouse model of Alzheimer's disease. Front Pharmacol. 2017:8:847.

31. Sudha S, Lakshmana MK, Pradhan N. Changes in learning and memory, acetylcholinesterase activity and monoamines in brain after chronic carbamazepine administration in rats. Epilepsia. 1995;36(4):416-22.

32. Agarwal NB, Agarwal NK, Mediratta PK, Sharma KK. Effect of lamotrigine, oxcarbazepine and topiramate on cognitive functions and oxidative stress in PTZ-kindled mice. Seizure. 2011;20(3):257-62.

\section{Submit your manuscript to a SpringerOpen ${ }^{\circ}$ journal and benefit from:}

- Convenient online submission

- Rigorous peer review

- Open access: articles freely available online

- High visibility within the field

- Retaining the copyright to your article

Submit your next manuscript at $\boldsymbol{\nabla}$ springeropen.com 